\title{
De qué te ríes: la farsa moderna
}

\author{
José de Jesús Manuel Vargas Escobedo \\ jjvargas@capomo.uson.mx
}

\section{Introducción}

La farsa moderna se configura a partir de la aparición en 1896 de Ubú Rey de Alfred Jarry (Laval 1873 París, 1907). Esta farsa provocó un zafarrancho el día de su estreno, equiparable sólo con lo sucedido sesenta y seis años atrás durante la presentación de Hernani obra de Victor Hugo que significó la victoria del romanticismo en Francia; Ubú Rey, por su parte, representó la propuesta para incorporar el sin sentido, lo irracional y el absurdo como fundamento y soporte de la creación artística (Vargas, 2016).

La risa en el final decimonónico, ya con el pensamiento moderno consolidado, se convierte en objeto de estudio para dos de las inteligencias más influyentes durante y después de la transición entre siglos: Sigmund Freud (Príbor, 1856-Londres, 1939) y Henri Bergson (París, 1859 - 1941).

Aristóteles es, sin embargo, el referente primario para comprender cómo la risa se desencadena como efecto de lo cómico. Toda discusión posterior toma como punto de partida lo dicho por el estagirita en su famosa Poética; así repetimos que la risa como efecto de lo cómico proviene de observar lo humano ridículo:

... imitación de los hombres peor de lo que son; peor, en efecto, no en cuanto a algunas y cada tipo de faltas, sino sólo referente a una clase particular, lo ridículo, que es una especie de lo feo. Lo ridículo puede ser definido acaso como un error o deformidad que no produce dolor ni daño a otros; la máscara, por ejemplo, que provoca risa, es algo feo y distorsionado, que no causa dolor (p. 6).

Lo cómico es una categoría estética que se expresa con plenitud en la comedia como subgénero dramático, pero cuando entramos al terreno de la farsa ellector- espectador ríe por un asesinato, un accidente o una violación, es decir, por eventos o acciones que sí provocan daño o dolor.

Los teóricos del drama en gran parte de los casos hablan del "efecto cómico" indistintamente para referir lo que provoca risa en la comedia y en la farsa, pero hay diferencias sustanciales. Tomando como ejemplo, la farsa Ubú Rey, en esta exposición expondré las características que configuran la farsa moderna y que explican en gran medida el porqué de la risa provocada.

\section{Ubú Rey de Alfred Jarry}

Bergson, a quien probablemente Jarry conoció y leyó, y a quien Freud refuta, publica en 1900 su ensayo La Risa en él se infiere como hipótesis que la risa es un fenómeno de la inteligencia, de la razón, pero también admite la participación de la intuición en la generación de imágenes provocadoras del mismo efecto. Bergson concede gran valor a la experiencia y a la memoria; desde esa óptica es comprensible la asociación que se plantea entre lo cómico y la infancia. En este ensayo, el autor sintetiza un mecanismo para generar el efecto disparador de la risa: "Se obtendrá un efecto cómico siempre que transporte a otro tono la expresión natural de una idea” (Bergson, p. 45). Pero advierte que cualquier teoría sobre lo cómico es incapaz de aprender el fenómeno en una definición. Freud, por su parte, sostiene que la experiencia con lo cómico es posterior a la infancia y se forma como comparación entre el adulto y el niño: “(...) el carácter específico de la comicidad era precisamente este renacimiento de lo infantil, y considerar lo cómico como «la perdida risa infantil» reconquistada” (Freud, p. 130).

Y añade más adelante:

... la comparación productora de lo cómico no tiene necesidad de despertar todo el antiguo placer y todo el antiguo juego infantiles, sino que bastará con que toque a la esencia general infantil y quizá hasta al dolor infantil mismo. Con esto nos apartamos de Bergson... (Freud, p. 131).

Freud, a diferencia de otros autores, desliga conceptualmente al chiste, al humor y a lo cómico, para concluir que, independientemente de sus diferencias, en los tres casos el propósito es obtener placer mediante la reconquista de una actividad anímica y una euforia propias de la niñez: "el estado de ánimo de nuestra infancia, en la que no conocíamos lo cómico, 
no éramos capaces del chiste y no necesitábamos del humor para sentirnos felices en la vida” (Freud, p. 137).

Pocos años antes de este debate, Jarry diseña a Padre Ubú, el protagonista de la farsa: posee un vientre tan abultado que prácticamente hace del torso una esfera, simbolizando el predominio de las bajas pasiones; su cabeza termina en punta, de modo que bien podría representar un cerebro del tamaño de un frijol donde la razón está ausente; si hay conciencia, ésta se encuentra en el estómago.

Padre Ubú y su trayectoria simbolizan, con gran eficacia, la traición, tiranía, torpeza y cobardía de los humanos en el ejercicio del poder y en la forma de obtenerlo, además del conjunto de vicios comunes a los hombres. Padre Ubú es la expresión simbólica de la humanidad entera.

Padre Ubú, desde una perspectiva psicoanalítica simboliza al hombre que no ha superado al "perverso polimorfo", descrito por Freud como el recién nacido insaciable, egoísta y ajeno a toda norma, pues no reconoce la existencia del otro. Desde Bergson, Padre Ubú se pude comprender como un diseño que emplea diversas estrategias retóricas para dar cuenta de los vicios humanos; Padre Ubú como antítesis de la inteligencia y prototipo del instinto.

Vayamos, pues, a la estructura y mecanismo de la farsa para entender mejor la risa que de ella se desprende.

\section{Estructura y mecanismos de la farsa}

Estudiar los mecanismos de la farsa implica recuperar la vieja discusión sobre lo verosímil, sobre la mímesis y su relación con la realidad y la imaginación. La realidad es siempre el punto de partida para juzgar la ficción; sin embargo, la ficción es una convención que tiene como espacio de realización a la imaginación; la verdad no es el criterio para validarla sino la verosimilitud y ésta se logra por la coherencia interna del discurso, coherencia que permite al lector establecer una relación de complicidad con el texto, traducida en credibilidad.

Lo relatado por la ficción puede coincidir con eventos de la realidad y con la forma en que han sucedido, pero también puede mostrar historias cuya forma dista mucho de parecerse a nuestra experiencia y percepción de las cosas reales, por ejemplo: que el planeta sea bombardeado por rocas provenientes del espacio exterior, es algo que sucede a diario, estadísticamente es probable; que se envíe una nave para destruir una gran roca antes de colisionar con la tierra, no es probable, pues no ha sucedido, pero es posible en tanto que se posee la tecnología necesaria para intentarlo; que un hombre con capa vuele hacia el aerolito y lo destruya a puñetazos resulta imposible en el terreno de lo real.

Lo imposible en la realidad, es posible y creíble en la ficción; la lógica interna con que se construye el relato, otorga a éste verosimilitud. Lo probable, lo posible y lo imposible se convierten, así, en categorías que auxilian en la definición de un género y un estilo.

En la farsa pueden coexistir, como materiales de construcción, personajes, objetos y situaciones probables, posibles e imposibles.

Uno de los pocos libros donde Luisa Josefina Hernández expone parte de su teoría de géneros dramáticos es Beckett: sentido y método de dos obras (1997). En este texto, la autora analiza las obras Esperando a Godot y Fin de partida; aquí, conceptualiza al teatro del absurdo como una dramaturgia hecha en la tesitura de la farsa, porque se corresponde con los criterios del género que expondré a continuación.

De acuerdo con la autora, la farsa tiene la versatilidad de asociarse con cualquier género dramático, la trayectoria de sus personajes y los temas tratados pueden ser equiparables con lo que puede suceder en los otros seis géneros mayores -tragedia, comedia, tragicomedia, pieza, melodrama y teatro didácticosin embargo, a diferencia de la comedia se aleja del realismo mediante el empleo de materiales no probables en la realidad:

¿Es probable que Lisístrata hubiera podido organizar la confabulación de mujeres tal como la describe Aristófanes? ¿Es probable que de ser así hubiera tenido éxito? (...) Lo verdaderamente probable es que todas hubiera sido severamente castigadas por traición a la patria (Hernández, 2011, pp. 214-215)

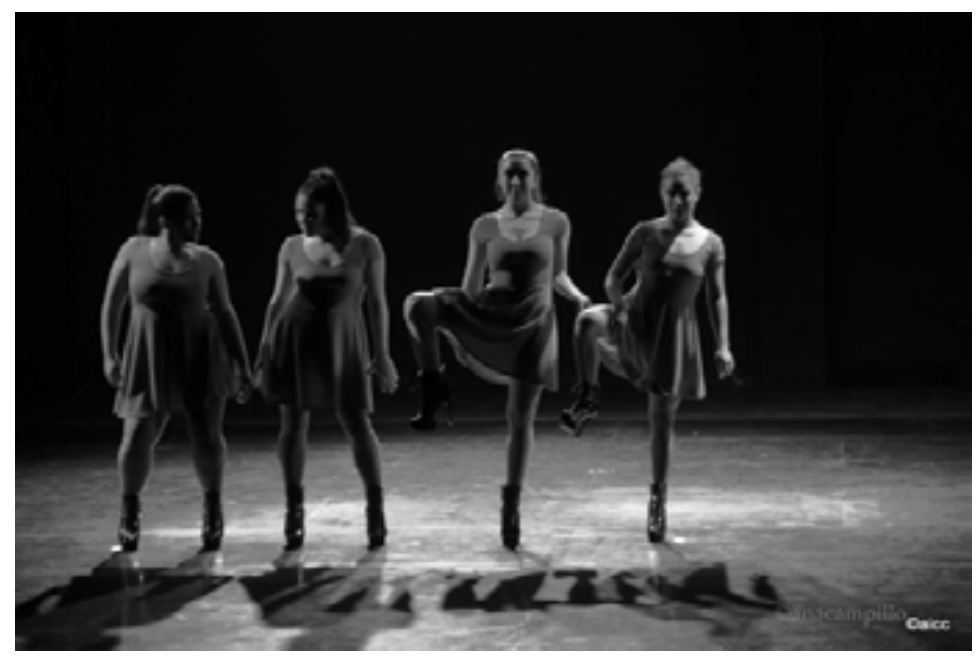

Ana Isabel Campillo 
La farsa opera con un registro tonal que provoca risa al asociar intenciones satíricas o paródicas con lo grotesco y con la fealdad. En el registro fársico la presentación de dolor, vergüenza, enojo, escarnio, profanación escándalo, transgresión, injusticia, es motivo de risa. Pero, risa que provoca desahogo, shock liberador, sin compromiso emocional con el protagonista ni sentimientos de culpa, es una forma de catarsis.

El mecanismo de la farsa en oposición a la operación mimético-referencial aristotélica es, de acuerdo con los intérpretes de Hernández, la sustitución. Espinoza (1980) lo explic(arafarsa)... cuyo mecanismo primordial es una substitución de la realidad por un concepto visual y verbal semejante al símbolo que es perfectamente reconocible para quien lo percibe, pero que obviamente no es la realidad misma, no propone su equivalencia sino ocupa su lugar.

Poner a un gorila vestido con uniforme militar en actitud violenta contra civiles, es una imagen recurrente durante las dictaduras latinoamericanas; en este ejemplo se aprecia con claridad el mecanismo de sustitución. (p. 11)

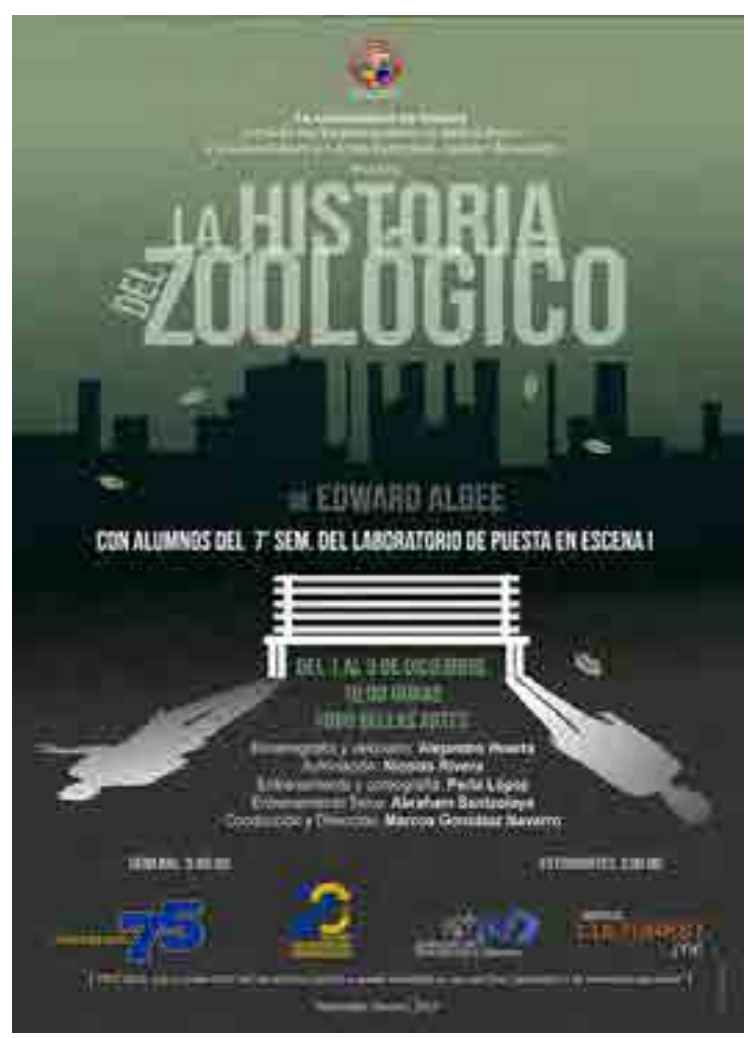

La hipérbole contenida en el militar-gorila provocaba risa no porque se castigara el vicio, como en la comedia, sino porque el vicio se lleva a los extremos con signos visuales y verbales que muestran la brutalidad y la violencia del opresor; su representación satírica es una pequeña revancha, irracional sí, pero la risa como efecto opera como liberación catártica.

Para Reyes (2002), la conceptualización sobre el mecanismo de sustitución, como operación intelectual distintiva de la farsa, que hace Hernández, es una "propuesta teórica absolutamente original en la historia de la teoría dramática”. Efectivamente, el mecanismo de sustitución es la estrategia de escritura dramática que permite construir fábulas cuyas situaciones, personajes y lógica no se parecen a los de la realidad (los sustituyen), como sucede con la alegoría; sin embargo, la realidad no desaparece, es revelada al lector-espectador, consciente o inconscientemente, ya como interpretación simbólica ya como experiencia sensorial desencadenante, en ambos casos, de una catarsis.

La farsa, concuerdan la mayoría de las fuentes consultadas, recurre a un lenguaje hiperbólico, emplea retruécanos e ironías, suele estar plagada de expresiones groseras y alusiones escatológicas; las situaciones planteadas son absurdas, a veces se presenta como parodia y, también, es común encontrar en ella intenciones satíricas; la acción dramática avanza con gran celeridad, Pavis, (1980), apunta al respecto:

Esta rapidez y esta fuerza otorgan a la farsa un criterio subversivo: contra los poderes morales o políticos, los tabúes sexuales, el racionalismo y las reglas de la tragedia. A través de la farsa, el espectador se venga de las limitaciones de la realidad y de la sabia razón. Los impulsos y la risa liberadora triunfan ante la inhibición y la angustia trágica, bajo la máscara de bufonería y de la 'licencia poética'." (pp. 218-219)

La farsa emplea el grotesco como recurso estético privilegiado y la risa liberadora es el efecto provocado como catarsis, en oposición a la piedad y el terror de la tragedia.

La historia y su representación escénica se expresan en la farsa como oposición a la mímesis realista, la farsa recurre a lo grotesco, a la distorsión y exageración, es el género donde lo imposible puede 
ocurrir, o bien, es el género donde sucede todo lo que es posible crear con la imaginación en los territorios del absurdo y la fantasía; trasciende por tanto la descripción realista.

Si bien es cierto que muchas de las características mencionadas para la farsa pueden encontrarse tanto en el drama satírico como en la tradicionalmente llamada comedia antigua, que tiene en Aristófanes a su principal exponente, es en la Edad Media cuando se acuña la denominación farsa para identificar pequeñas obras bufas intercaladas entre episodios de los Misterios; la farsa es en un primer momento y de acuerdo con su etimología una obra de relleno, pero posee tal arraigo en el público popular, que rápidamente cobra autonomía; la farsa será la única modalidad teatral que trasciende su época y que en pleno siglo XX es el soporte del llamado teatro del absurdo. En la época pre helénica de la cultura romana, hacia el siglo IV a. C., aparece una de las cuatro modalidades de la comedia latina: la fabula atellana; esta modalidad toma el nombre de Atella, pueblo cercano a Nápoles, lugar donde se origina. En la Roma antigua se sustituye la palabra comedia por fabula.

Palliata y togata son las formas de la comedia literaria de influencia helena que desplazan a la atellana, modalidad propiamente itálica, por considerarla vulgar y más propia de campesinos; el mimo será la cuarta modalidad.

La fábula atellana es también, como el drama satírico, un antecedente importante de la farsa; en ella, el gesto y la palabra son hiperbólicos, es obscena, los actores emplean máscaras y representan personajes con diseño grotesco (Gómez, 2003, pp. 244-245); estos son rasgos compartidos por la farsa, sin embargo, su modelo de acción dramática es antecedente directo de la Commedia dell'Arte renacentista, pues como esta última, la atellana se basa en la improvisación; otra semejanza radica en que sus personajes son tipos fijos como "el tonto", "el glotón”, "el viejo” y "el jorobado", a partir de los cuales se construye la acción sustentada en equívocos y confrontación entre lo rural y lo urbano.

El mimo latino es probablemente una derivación de la fábula atellana y del mimo de tradición griega; surge hacia finales de la República y cobra relevancia durante el imperio. $\mathrm{Al}$ igual que la farsa medieval es una representación breve que servía como intermedio de obras mayores; la danza y la gesticulación exagerada son sus rasgos originales, pero con el tiempo surgirá un mimo literario más adecuado al gusto de los patricios; conservará sin embargo y en forma predominante la exageración de los movimien- tos corporalesEherequadisoobsceminyolubrididddelemento esencial residía en los signos correspondientes a la expresión corporal, en concreto mímica, gesto y movimiento, (...). De esta particularidad derivan consecuencias que atañen de manera fundamental a los actores y a la actuación (...)

[Se] considera como práctica admitida el que las actrices se desnudasen en el escenario al final de la representación. (López y Pociña, 2007, p. 313)

Los temas del mimo son de orden cotidiano, con tratamiento satírico: maridos engañados, cambios inesperados de fortuna, amores licenciosos. El mimo desaparece a la llegada del cristianismo como religión hegemónica del imperio.

La farsa medioeval hereda del mimo una actoralidad grandilocuente y el empleo del cuerpo, por encima del lenguaje verbal, como principal productor de signos, además de la función de "relleno" como intermedio de una obra mayor, usualmente de corte religioso.

A pesar de su arraigo entre el pueblo, la farsa padecerá un letargo de siglos provocado, primero, por la censura eclesiástica y, luego, por el redescubrimiento del mundo clásico durante el Renacimiento y hasta el final del siglo XVIII, periodo en que se cultivan tragedia, comedia y tragicomedia de manera preponderante, bajo el influjo del pensamiento ilustrado.

El romántico Johann Ludwig Tieck (1773 - 1853), escritor que incursionó en la narrativa y la dramática, famoso por cuentos como El Gato con Botas, obra de la cual el autor escribiría, también, una versión para teatro, es de los pocos escritores que en su época se atreven a escribir comedia y farsa. Pero el sentido del humor sobre el escenario parece estar fuera de la sensibilidad romántica. La obra dramática de Tieck, en esta tesitura, es considerada de menor valía por sus contemporáneos y será prácticamente olvidada con la llegada del realismo.

Tres obras de Tieck resultan significativas para la renovación del lenguaje y estructura propios de la farsa: Der gestiefelte kater (El gato con botas, 1797); Prinz Zerbino, oder Die Reise nach dem guten Geschmack (El príncipe Zerbino, o Viaje en búsqueda del buen gusto, 1797) y Die verkehrte Welt (El mundo al revés, 1797). Víctor Grovas (2001), estudioso del autor, opina que en ellas “Tieck contribuye con osadía 
al resquebrajamiento de las unidades aristotélicas, $\mathrm{y}$ experimenta con diversos derroteros estructurales: se burla de todo y de todos” (p. 117).

Primero en El mundo al revés, al finalizar el siglo XVIII, y después en Ubú Rey de Alfred Jarry (1873-1907) en 1896, encontramos el origen de la farsa moderna; Tieck y Alfred Jarry innovan la estructura dramática del género, ambos coinciden en el empleo de la sátira como estrategia discursiva y en el uso del grotesco como vehículo de expresión. Anecdóticamente también existe coincidencia en el diseño de sus protagonistas, ambos son seres ambiciosos que, al ejercer el poder, actúan con tiranía y arbitrariedad hasta el absurdo, la diferencia entre ambos está en el uso privilegiado e intencionalmente abusivo que Jarry hace de la intertextualidad y del lenguaje escatológico.

Tieck escribe El mundo al revés en 1797, obra cuya fábula se monta sobre un mito de la Grecia clásica, con la inserción anacrónica de personajes de la Comedia dell' arte: Scaramuccio se hace pasar por Apolo mediante el mecanismo de suplantación de identidad y de este modo toma control del Parnaso. Este planteamiento nos remite al tipo de anécdota propio de la comedia de enredo, pero, al mismo tiempo, se aleja de toda posibilidad realista al vincular en un tiempo, épocas distantes y personajes disímbolos como dioses, cómicos renacentistas, bufones isabelinos y burgueses del drama decimonónico que recuerdan diversas tradiciones teatrales como tragedia y comedia griegas, comedia del arte italiana y teatro shakespeareano.

Ubú Rey es construido con recursos estéticos del grotesco; ni la belleza ni la imitación "objetiva” de la realidad (ilusión de realidad) son opciones para presentar un ser despreciable, identificable en términos simbólicos con el hombre burgués. Padre Ubú es un personaje arquetípico que concentra los vicios humanos; egoísmo, cobardía, crueldad e ignorancia son el motor de sus actos. Jarry ofrece una historia donde se alude a otra historia conocida para dar estructura a un discurso distinto; al fin de cuentas, Macbeth es un títere miedoso y manipulable, que bien puede reconstruirse añadiendo el resto de vicios humanos tomados por retazos de decenas de otras historias.

La tragedia Shakespeareana es parodiada por Jarry en un registro fársico, re-diseña los personajes y la fábula de la tragedia escocesa, la adereza con retacería de Hamlet y Julio César -verbigracia la aparición del espectro del rey demandando venganza o la conspiración de Casio y Bruto-, todo ello, en un registro grotesco, caricaturesco y absurdo. Con Tieck y Jarry quedan establecidas las reglas del juego, sustentadas en la libertad absoluta para la creación escénica, en un género obligado a construirse desde la imaginación, desde la capacidad para simbolizar la realidad, muy lejos de la estética realista, y es esta distancia la que permite objetar la idea muy difundida de que la farsa es una derivación de la comedia: Aristóteles no se refiere como comedia a la producción dramática de Aristófanes porque seguramente nunca la vio representada; Aristófanes escribe farsas $y$, en consecuencia, este subgénero de la dramática precede a la comedia.

No es extraño que teatralidad y espectacularidad hagan de la farsa el género más popular, tampoco extraña que haya sobrevivido al menosprecio de muchos intelectuales; Usigli (2005), el prestigiado dramaturgo que desarrolló en México la idea de profesionalizar al autor dramático, mediante el conocimiento de las teorías dramáticas expresa en Escritos sobre la historia del teatro en México:

\section{... la farsa, como género dramático, me interesa poco, pero encuentro legítimo que la haga quien tiene simpatía por ella (...) La farsa, a pesar de todos sus valores de risa, huele siempre un poco a viejo. Aunque destaca con satírica agudeza los defectos y las debilidades y los vicios del hombre, parte siempre de un principio de deshumanización que la hace profundamente desagradable, $\mathrm{y}$ da al personaje los límites del muñeco. (p. 334)}

\section{A manera de conclusión}

Es comprensible que el hablar de la farsa desde las trincheras del realismo implique menosprecio por este género, como lo hace Usigli; efectivamente el diseño de los personajes fársicos no se ocupa de su psicología, no construye individualidades, pero eso no significa que deshumanice al personaje; el personaje fársico opera como generalización de algún rasgo humano, es arquetípico, pone en relieve un vicio o un defecto y los desarrolla al extremo; ello explica la complejidad en la formalización de los personajes y del espacio físico en que habitan y actúan

La farsa, menospreciada por gran parte de las élites intelectuales, se consolida en el siglo XX como género dramático, a pesar de sus detractores, por su 


\section{INFORMES DE INVESTIGACIÓN}

\section{Bibliografía}

Aristóteles. (s/f). Poética. Retrieved 2011 14-Noviembre from Escuela de Filosofía Universidad ARCIS | Editorial: http://www.philosophia.cl/biblioteca/aristoteles/poetica.pdf

Bergson, H. (s.f.). La Risa. Recuperado el 26 de diciembre de 2016, de CIIEs Región 10 Pcia. Buenos Aires: https://ciie-r10.wikispaces.com/file/view/2.+Bergson_La+risa.pdf

Espinoza, T. (1980). Presentación. En J. Kenneth Knowles, Luisa Josefina Hernández: teoría y práctica del drama. México: Universidad Nacional Autónoma de México.

Freud, S. (s.f.). El chiste y su relación con el inconciente. Recuperado el 27 de diciembre de 2016, de El ortiba, colectivo de cultura popular: http://www.elortiba.org/pdf/freud_chiste.pdf

Gómez, J. (2003). Studiosa Roma: los géneros literarios en la cultura romana: Notas para su explicación, de Apio Claudio a Isidoro. Barcelona: Universitat Autónoma de Barcelona.

Grovas, V. (2001). El Mundo al Revés y la Sonrisa Romántica: Un viaje por la comedia de Ludwig Tieck. México: Facultad de Filosofía y Letras UNAM.

Hernández, L. J. (1997). Beckett: sentido y método de dos obras. México: Fac. de Filosofía y Letras. UNAM.

Hernández, L. J. (2011). Un enfoque teórico de la farsa. En F. Reyes, \& N. Edith, Los frutos de Luisa Josefina Hernández: Aproximaciones Escritos de teoría dramática (pp. 213 - 219). México: Universidad Nacional Autónoma de México.

López, A., \& Pociña, A. (2007). Comedia romana. Madrid: Akal.

Pavis, P. (1980). Diccionario de teatro: Dramaturgia, estética, semiología. (F. d. Toro, Trans.) Barcelona: Paidos.

Reyes Palacios, F. (2002). Algunas aportaciones de Luisa Josefina Hernández a la teoría dramática. Recuperado el 13 de Agosto de 2012, de Repositorio Institucional Universidad Veracruzana: http://cdigital.uv.mx/handle/123456789/4662

Usigli, R. (2005). Teatro Completo de Rodolfo Usigli V: Escritos sobre la historia del teatro en México. México: Fondo de Cultura Económica.

Vargas, J. d. (8 de Abril de 2016). UBÚ REY 1896: ORIGEN DE LA FARSA MODERNA. Tesis para obtener el grado de Maestría en Humanidades. Universidad de Sonora. Hermosillo, Sonora, México.

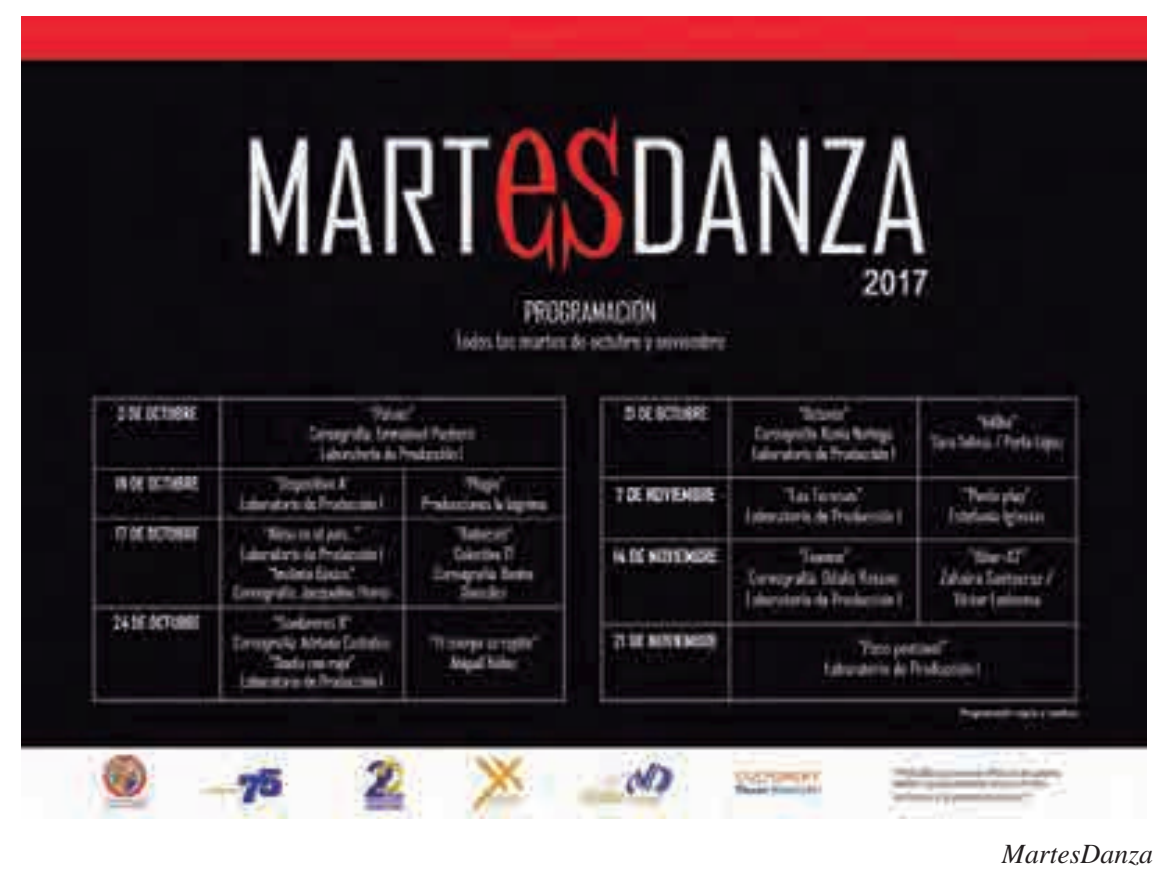

